INVESTIGACIÓN

\title{
DIAGNÓSTICO DEL CURSO DE FUNDAMENTACIÓN CICLO VIGILANTE EN EL SECTOR DE SEGURIDAD PRIVADA EN COLOMBIA*
}

\section{DIAGNOSIS OF THE FOUNDATION COURSE WATCHING CYCLE IN THE SECURITY SECTOR PRIVATE IN COLOMBIA}

Recibido: 10 de febrero de 2018

Ing. Ma. Andrea Cortes-Barreto*

Evaluado: 29 de marzo de 2018

Aprobado: 12 de mayo de 2018

\section{RESUMEN}

El crecimiento del sector de seguridad privada en América Latina en la década de los noventa y los cambio en las organizaciones han provisto la necesidad de reflexionar acerca del contenido curricular en la formación de los guardias de seguridad por el rol que desempeña en las organizaciones y la sociedad. Por consiguiente surge la necesidad de hacer una revisión del currículo y normatividad del Curso de Fundamentación Ciclo Vigilante en Colombia y Argentina, por lo que se realizó una exploración del estado del arte de la importancia de la formación en el contexto laboral desde la Edad Antigua pasando por modelos de pensamiento administrativo como la Administración Científica, la Teoría de la Administración Operacional Moderna, las Ciencias del

* Este documento es producto de los resultados de una investigación de carácter reflexiva analítica del sector de seguridad privada y la formación por competencias por parte de la autora.

** Ma. Andrea Cortes Barreto (https://orcid.org/0000-0002-8944-9503) es Administradora de Empresas e Ingeniera Industrial de la Universidad Nacional Abierta y a Distancia- UNAD, Especialista en Docencia Universitaria y en formación en Especialista Alta gerencia de la Universidad Militar Nueva GranadaUMNG, y docente de la UNAD en Bogotá-Colombia. La correspondencia en relación con este artículo debe dirigirse al correo electrónico de contacto macortesb@hotmail.com. 
Comportamiento con los estudios de Elthon Mayo y J.Roethlisberger, la Teoría Estructuralista de Max Weber, la Teoría de Sistemas y teorías de la administración moderna de Pete F. Drucker.

En concordancia se identifica que los datos estadísticos de Colombia y Argentina referente al bajo nivel de formación de los guardias de seguridad es evidente que no cuentan competencias específicas para cumplir con las exigencias en el entorno laboral en el sector de seguridad privada. Por ende, en el contexto colombiano y en particular en las escuelas capacitación y entrenamiento en seguridad privada requieren formar seres integrales que estén en capacidad de actuar profesionalmente frente a los retos de las organizaciones y clientes, por lo que se concluye que el enfoque socioformativo se amolda a las necesidades de las empresas en la medida que gestiona los recursos y espacios para formación integral de los guardias de seguridad, para que estén en la capacidad de solucionar los problemas actuales y futuros en los diferentes contextos (laboral, sociedad, familiar).

Palabras Claves: Competencias, Currículo, Curso de Fundamentación, Formación Integral, Vigilancia, Vigilante y Seguridad Privada.

\begin{abstract}
ABSTRAC
The growth of the private security sector in Latin America in the 1990s and changes in organizations have provided the need to reflect on the curricular content of security guards' training because of their role in organizations and society. The methodology used is the revision of the curriculum and normativity of the Foundation Course CycleSurveillance in Colombia and Argentina, where an exploration was made of the state of the art of the importance of training in the labor context from the Ancient Age through administrative thought models such as Scientific Management, the Theory of Modern Operational Administration, the Sciences of Behavior with the studies of Elthon Mayo and J. Roethlisberger, the structuralist theory of Max Weber, the theory of systems and the modern thinkers of administration whose is represented by Pete F. Drucker.
\end{abstract}

It is clear from the statistical data of Colombia and Argentina regarding the low level of training of security guards that they do not have specific competencies to comply with the requirements of the private security sector in the working environment. Therefore, in the Colombian context and particularly in schools, private security training and education requires the formation of comprehensive people capable of acting professionally in the face of the challenges faced by organizations 
and clients. Therefore, the socio-educational approach is adapted to the needs of companies as far as they manage the resources and spaces for comprehensive training of security guards, so that they can solve current and future problems in different contexts (labor, society, family).

Keywords: Skills, curriculum, foundation course, integral formation, surveillance, security guard and private security.

\section{INTRODUCCIÓN}

Este ensayo tiene la intencionalidad de realizar una revisión del currículo sobre las competencias laborales del vigilante o vigilador (Argentina) agentes de seguridad (en literatura internacional se menciona como) entorno al impacto en su labor profesional. Purpura (2006) afirma" en numerosos informes de investigación y publicaciones, se ha señalado la necesidad de contar con más y mejores programas de capacitación del personal dentro de la industria de la seguridad" (p. 52). Desde la década de los noventa, se reconoció la necesidad de fortalecer los programas de capacitación a los vigilantes con el objetivo garantizar un desempeño superior de mediante el currículo integral. Purpura (2006), "en Estados Unidos se propusieron, a nivel de legislación federal, algunos temas que deberían incluirse en la formación de oficiales de seguridad: leyes, seguridad y protección contra incendios, primeros auxilios, redacción de informes" (p.53).
En Colombia, la Superintendencia de Vigilancia y Seguridad Privada es un organismo de orden nacional creada en el año de 1993, a la cual se le dio la facultad para ejercer control, inspección y vigilancia del sector de Seguridad Privada en el territorio nacional en los diferentes servicios que prestan las empresas que cuentan con licencia vigente para operar los servicios que van desde la vigilancia con armas, sin armas, medios tecnológicos, caninos, transporte de valores, asesoría, consultoría e investigación, servicios de blindaje, servicios comunitarios y las escuelas de capacitación y entrenamiento. Este documento aborda en especial una descripción crítica del currículo del curso de Fundamentación Ciclo Vigilante como criterio esencial para ejercer dentro de un campo laboral como vigilante.

El vigilante es una persona natural que cuenta con credenciales para ejercer este oficio y tiene por misión proteger, salvaguardar, inspeccionar ingreso y salida (personas y bienes muebles) 
de los inmuebles donde prestan servicio con la finalidad de mitigar, prever, disuadir hechos delictivos que atenten con el bienestar de las personas e instalaciones. El sector de seguridad privada según Baracaldo (2014) "Colombia cerró el año 2013 con 4.596 servicios de vigilancia y seguridad privada registrados y un total de 230.000 personas vinculadas" (p.258); estas cifras son la razón que fundamenta la necesidad de profesionalizar el personal que trabaja en el sector de seguridad privada en Colombia. Al mismo tiempo, en el panorama internacional Estados Unidos no es ajena este crecimiento como lo afirma Nain:

El sector más emblemático del apogeo de la sociedad civil armada es la seguridad privada, que hoy experimenta un auge de proporciones históricas. El negocio global de la seguridad está creciendo a un ritmo tal, que se calcula que, de un volumen de 100 mil millones de dólares en 2001, habrá pasado a 400.000 millones en 2010. (Baracaldo, 2014, p.261).

Como se puede notar en los últimos años el negocio de la seguridad ha aumentado, es decir, las empresas han comenzado a ver la necesidad de contar con guardas de seguridad para proteger sus recursos frente a tanta inseguridad latente en los diferentes contextos, por lo que ha hecho que a su vez aumenten las instituciones encargadas de gestionar los conocimientos en temas de seguridad.

\section{ANTECEDENTES HISTÓRICOS DE LA PROFESIONALIZACIÓN DE ARTES Y OFICIOS}

Los procesos de formación en el ámbito de las artes y oficios han ido de la mano con el desarrollo económico y social de la humanidad desde tiempos inmemorables y han sufrido grandes trasformaciones hasta la Edad Contemporánea, para poder suplir las necesidades organizacionales cada día más exigentes, que buscan contar con trabajadores profesionales y competentes que aporte a la sostenibilidad de las empresas.

En la Edad Antigua los saberes se transmitían de padres a hijos en los diferentes oficios y actividades esenciales para sobrevivir y atender las necesidades básicas de la tribu (alimento, abrigo, seguridad) en esa época en forma incipiente surge las primeras profesiones como la agricultura, la caza, el arte de la defensa y elaborar prendas; tanto mujeres y hombres empíricamente y a través de la experiencia en la ejecución de sus labores recibieron el reconocimiento dentro de la comunidad como una elite privilegiada. El proceso de la trasmisión de saberes contribuyo significativamente en el desarrollo de las comunidades primitivas en la medida que fueron la base de 
las culturas antiguas y al mismo tiempo, fueron un factor diferenciador entre ellas. Como lo afirma, Catalano, Avolio y Sladogna (2004) “los artesanos, quienes, especializándose en determinados tipos de productos o de materias primas, comenzaron a elaborar bienes de consumo y de trabajo. Así surgieron los tejedores, los herreros, los talabarteros, los constructores de grandes edificios" (p.24). En particular, en el Antiguo Egipto se destacaba por la construcción de grandes obras arquitectónicas donde ocupaban personal profesional denominados artesanos que empleaban técnicas y materiales para la edificación de esplendidos templos y pirámides.

Tiempo después en la Edad Media, los saberes de los artesanos se agrupaban en hermandad o cofradía que se caracterizaba por su estructura jerárquica vertical de enseñanza y aprendizaje dirigida por un maestro, quien poseía los conocimientos del oficio y quien tenía a su cargo los oficiales y aprendices bajo una relación de subordinación. "La formación de los artesanos se centraba en el aprendizaje directo, in situ, a través del trabajo (taller-escuela), lo que permitía eliminar prácticamente el coste de la educación al producir rendimientos efectivos durante la instrucción" (Pereira y Sousa, 1990, p. 219). El maestro artesano era quien tenía una amplia visión sobre los costos, los materiales, las técnicas, diseño de los productos, la distribución de actividades en función de las habilidades de sus oficiales y aprendices con la finalidad de elaborar el mejor producto. Al mismo tiempo, el maestro artesano era quien instruía y evaluaba el desempeño de su personal para darlo a conocer entre el gremio, solo un selecto grupo de individuos de desempeño alto superior llegaban a ostentar el grado de maestro.

A finales siglo XVIII, en Europa se gestó profundas modificaciones en materia de transferencia de saberes y la estructura de la elite artesanal debido a la llustración. Según Pereira y Sousa (1990) "en España son buen ejemplo de ello las opiniones de Campomanes y Jovellanos que arremetieron ferozmente contra las viejas estructuras gremiales y pusieron de manifiesto la necesidad de instaurar un nuevo tipo de educación técnica" (p. 220). En Francia 1780 se levanta el Conservatorio de Artes y Oficios, tiempo después en otros países como Prusia, España, Inglaterra se fundan sus equivalentes. Nacen las Escuelas de Artes y Oficios donde se legitimaba la enseñanza de las artes y oficios y en sus currículos se imparte lecciones de física, química, dibujo, geometría aplicados a los contextos artesanales e industriales de la época.

En cuanto a la Revolución Industrial, el rol maestro artesano se desdibujo y su rol protagónico perdió vigencia en el tiempo. Sin duda, 
la industrialización condujo a grandes cambios en los modelos de enseñanza de las habilidades en el trabajo (ciclos cortos formación), la forma de organización en los talleres (líneas de producción), la tecnología empleada para producir artículos (fabricación en serie y automatización procesos) que repercutió en la reducción de los costos de producción. En efecto, se rediseñan los oficios y surgen otros para atender las nuevas necesidades en las fábricas, que giran en torno de operar máquinas y equipos mecanizados; a diferencia en la Edad Media, en donde los talleres era fundamental conocer las materias primas y técnicas para elaborar productos que implicaban años de aprender por parte de los oficiales y aprendices.

En relación con el siglo $X X$, las escuelas de ingeniería y administración de empresa difunden y aplican los modelos de pensamiento administrativo como: la Administración Científica, la Teoría de la Administración Operacional Moderna, las Ciencias del Comportamiento con los estudios de Elthon Mayo y J.Roethlisberger, Teoría Estructuralista de Max Weber, la Teoría de Sistemas y dentro de los pensadores modernos de la administración se encuentra Pete F. Drucker como un personaje notable en la esfera internacional.

De hecho, Frederick W. Taylor (1856-1915) es conocido como el padre de la Administración
Científica, cabe destacar que él se desempeñó desde el rol de aprendiz hasta ingeniero jefe, está experiencia le permitió contar con una visión global de las organizaciones para analizar las relaciones discrepantes entre los trabajadores y empleadores, los resultados de los trabajadores calificados, la productividad en términos de los tiempos de ejecución de las labores por parte de los obreros. Por ejemplo, en los resultados encontrado por Taylor, descritos por Ramírez (2012 p. 134) "la producción de uno a cuatro, es decir, que mientras un obrero calificado podría producir cuatro unidades, el obrero no calificado apenas producía una". Es evidente que la aplicación del método científico al contexto administrativo permitió replantear los roles del trabajador, el sistema de estímulos económicos (mejor remuneración por el cumplimiento de las metas operacionales), motivacionales (coordinación y trabajo en equipo) entendido la armonía entre las actividades en la organización, los procesos de capacitación y entrenamiento que repercuten en sostenibilidad financiera de las empresas y su perpetuidad en el tiempo.

El ingeniero Henri Fayol (1841-1925) se le conoce como el padre de la Administración Positiva - Teoría de la Administración Operacional Moderna, durante el Congreso de la Sociedad Industrial Minera difundió su investigación que incorpora los elementos universales de la admi- 
nistración agrupados en operaciones: técnicas (producción) comerciales (compras- ventas), financieras (gestión de recursos económicos), contable (registros de operaciones económicas), seguridad (seguridad social e industrial) y función administrativa entendidas " como la previsión o planeación, organización, dirección o mando, coordinación y control" (Ramírez, 2010, p. 166). La función administrativa es el motor dinamizador que se utiliza desde el nivel gerencial, con la finalidad de armonizar las actividades de la empresa y a su vez, contribuir a la sostenibilidad organizacional en el tiempo. Por otro lado, Fayol difundió la necesidad y aplicación de los aspectos estructurales y gerenciales que debían adoctrinar desde los niveles más altos hasta los niveles inferiores para generar un impacto significativo en la empresa.

Elton Mayo y F.J. Roethlisberger como exponentes de las Ciencias del Comportamiento, realizaron diversos estudios en la planta Hawthorne eléctrica en el periodo 1927 y 1932, para diagnosticar el impacto de la iluminación y otros factores sobre los colaboradores. No obstante, se presentaron dificultades metodológicas que fueron superadas por Mayo y sus investigadores mediante el cambio de "la iluminación para el grupo de prueba, modificar los periodos de descanso, recortar los días de trabajo y diversos sistemas de pago de incentivos no parecieron explicar los cambios de productividad". (Koontz, Weihich, y Cannice, 2012, p. 46). En efecto se concluyó la existencia de variables sociales como las relaciones interpersonales, la moral y el liderazgo efectivo repercuten notablemente en la productividad organizacional.

El represente de la Escuela Estructuralista es el sociólogo Max Weber, afirma la racionalización y distribución del trabajo constituye el factor que da vida a la una estructura organizacional llamada burocracia. Existe burocracia pública integrada por los servidores estatales y burocracia privada conformada mayormente por empleados de organizaciones de carácter privado. Weber planteo las características de la teoría de la burocracia, sobresalen tres por que aportan a este rastreo bibliográfico en especial, la división del trabajo, eficiencia en la aplicación normas técnicas y la especialización y profesionalización aplicadas al contexto empresarial implican: cada trabajador desarrolla actividades descritas en el cargo que guardan relación estrecha con los deberes, nivel jerárquico al que pertenece, remuneración salarial, la formación y entrenamiento para asegurar el máximo rendimiento organizacional. La Escuela Estructuralista estudio "las organizaciones desde el punto de vista de su estructura, de su funcionamiento y de los medios que utilizan para el logro de los objetivos" (Ramírez, 2010, p. 206). 
Escuela de Teoría de Sistemas, las organizaciones son entendidas como un sistema dinámico general que cuenta con subsistemas que interactúan (talento humano, contabilidad y finanzas, producción, etc.) para sobrevivir en un medio hostil. Chester Barnard afirma "la tarea de los gerentes es mantener un sistema de esfuerzo cooperativo en una organización formal" (Koontz, Weihich, y Cannice, 2012, p. 44). Por último, Peter Drucker y la Administración por Objetivos, recalco transcendencia de formular propósitos claros y que estos objetivos se puedan verificar mediante el cumplimiento. Al mismo tiempo, demostró interés apasionado por lograr trabajadores más productivos, capacidad de autonomía y toma de decisiones por parte de los colaboradores, replanteamiento del cómo ser humanos y no son máquinas, y "el aprendizaje organizacional, la capacitación y el desarrollo deben realizarse en todos los niveles de la organización: es un esfuerzo continuo". (Koontz, Weihich, y Cannice, 2012, p. 47).

\section{A raíz de los modelos desde la Administración} Científica hasta la Administración por Objetivos con el más notable autor Peter Druker han introducido en las empresas, nuevas perspectivas en la administración del personal que han jugado un papel en el rediseño y aplicación de mayores controles a los tiempos de producción de los trabajadores, motivación organizacional, división de trabajo por líneas de producción, un sistema jerárquico organizacional acorde a las habilidades de los trabajadores que está relacionado directamente con la remuneración económica a mayores competencias técnicas. Al mismo tiempo, los procesos de selección y formación identificaron la necesidad de capacitar al personal a raíz de su bajo nivel de académico (educación formal escolarizada) y su desempeño regular en las actividades que ejecutan los operarios que a su vez afectan los indicadores de productividad organizacionales.

Por ejemplo, el nivel de formación en educación básica (consta de la aprobación de nueve grados entre primaria y básica secundaria) de los vigilantes en Colombia el horizonte es lúgubre. Según estudios del Observatorio de Seguridad en Bogotá de la Cámara de Comercio del año 2008 indago a 822 vigilantes sobre el nivel de formación y la certificación del curso de la fundamentación para vigilantes y los resultados son preocupantes:

El $95 \%$ de los vigilantes encuestados son hombres. El 58\% se ubicó en un rango de edad entre 28 y 44 años. La mitad del personal de vigilancia encuestado finalizó sus estudios de secundaria y el $87 \%$ manifestó haber realizado por lo menos el curso básico o introductorio solicitado por la SuperVigilancia como requisito mínimo para su certificación. (Cámara de Comercio de Bogotá, 2008, p.7) 
En relación al nivel de formación y los requisitos para estudiar el curso de fundamentación para vigilantes se menciona en el artículo 42 de la Resolución 4973 de 2011 la persona interesada debe "tener aprobado, como mínimo, quinto grado de educación básica primaria para vigilantes; para Supervisor y Operador de medios tecnológicos undécimo año; para Escolta, Manejador Canino octavo grado" (Superintendencia de Vigilancia y Seguridad Privada, 20011, p.3). En el caso de las empresas de seguridad privada, que ofertan el curso de fundamentación para vigilantes a personas que cuenta con bajos niveles de formación académica tiene un reto a suplir mediante el plan curricular que debe garantizar un desempeño laboral superior en los guardias de seguridad en el entorno organizacional.

En otras palabras, la evolución desde la antigüedad hasta los actuales modelos de administrativos es evidente la preocupación por parte de las organizaciones contar con programas de capacitación y entrenamiento para sus colaboradores con la finalidad de potencializar su desempeño laboral y la orientación al logro de los objetivos organizacionales.

\section{MARCO NORMATIVO DEL CURSO DE FUNDAMENTACIÓN PARA VIGILANTES EN COLOMBIA}

Para comenzar, el sector de vigilancia y seguridad privada en Colombia tiene un gran potencial para estimular la generación de empleos, contribuir con la seguridad, la paz y bienestar de los habitantes del territorio nacional. Debido a esto, el compromiso por parte de las empresas de vigilancia, deben formar proactivamente a sus trabajadores con el fin de mejorar las competencias laborales.

En relación con el rastreo normativo de origen y las facultades otorgadas por la normatividad colombiana. En primer lugar, la Superintendencia de Vigilancia y Seguridad Privada en adelante SVSP se crea con la Ley 62 de 1993 específicamente en el artículo 34 que menciona que es una entidad pública de orden nacional adscrita al Ministerio de Defensa. Luego, en el Decreto 356 de 1994 surge la regulación del sector mediante el Estatuto de Vigilancia y Seguridad Privada que claramente define los lineamientos generales del sector para obtener el licenciamiento. Tiempo después, en el Decreto 2355 de 2006 en el artículo tres señala la competencia de SVSP acerca del portafolio de los servicios que regula en materia de:

1. Vigilancia y seguridad en todas sus modalidades, 2) de transporte de valores, 3) de blindaje para vigilancia y de seguridad privada, 4) comunitaria y especial de vigilancia y seguridad privada y 5) de capacitación y entrenamiento en vigilancia $y$ seguridad 
privada. (Superintendencia de Vigilancia y Seguridad Privada, 2006, p.1).

Hay que tener en cuenta, el centro de la revisión normativa y desarrollo de este documento gira en torno, a los servicios de capacitación y entrenamiento en vigilancia en la modalidad curso de fundamentación para vigilantes. La Superintendencia de Vigilancia y Seguridad Privada (2001) define el concepto de vigilante es "la persona natural que en la prestación del servicio se le ha encomendado como labor proteger, custodiar, efectuar controles de identidad en el acceso o en el interior de inmuebles determinados y vigilar bienes muebles de cualquier naturaleza" (p.1).

Particularmente, en el Decreto 356 de 1994, se menciona el concepto de capacitación y entrenamiento entendido como "los conocimientos y destrezas que se proporcionan para el ejercicio de las actividades que realiza el personal de los servicios de vigilancia y seguridad privada, en ejercicio de su función" (Superintendencia de Vigilancia y Seguridad Privada, 1994, p.11).

Es importante tener claro la competencia de la SVSP como máxima autoridad en el territorio nacional, en relación en emisión, control y vigilancia del cumplimiento de los lineamientos curriculares sobre los ciclos de formación en competencias laborales, materializado a través del Plan Educativo Institucional en Seguridad Privada denominado PEIS presentados al momento de la obtención de la licencia o renovación de la misma. En la Resolución 5679 de diciembre 2008 se propone el concepto de PEIS:

Es el documento de desarrollo institucional integral e individual que contiene el conjunto de condiciones mínimas respecto de los programas, actividades, infraestructura y medios con que deben contar las escuelas y departamentos de capacitación y entrenamiento en vigilancia y seguridad privada, con el fin de proporcionar conocimientos, habilidades y destrezas en términos de calidad al personal de los servicios de vigilancia y seguridad privada que permitan fortalecer y mejorar sus competencias laborales para el óptimo cumplimiento de sus funciones. (Superintendencia de Vigilancia y Seguridad Privada, 2008, p.2).

En efecto el concepto de PEIS, busca cumplir la intencionalidad de la SVSP que es garantizar un mínimo de elemento de calidad entendidos como direccionamiento estratégico (misión, visión, objetivos), medidas y acciones tendientes mitigar el riesgo durante las sesiones de entrenamiento, la metodología (presencial y/o virtual), sistema de autoevaluación y realimentación de docentes y estudiantes, 
bienestar institucional para la comunidad académica, contar con un convenio para realizar las prácticas de polígono, instalaciones físicas y tecnológicas, la documentación de proceso educativo en pro de la formación integral de los estudiantes.

\section{CURRÍCULO DEL CURSO DE FUNDAMENTACIÓN CICLO DE VIGILANTE EN COLOMBIA}

El Plan Educativo Institucional en Seguridad Privada PEIS es un requisito fundamental para la licencia o renovación. Por ende, la académica o escuela debe documentar detalladamente el plan curricular para cada uno de los ciclos de formación (vigilante, escolta, supervisor, operador de medio tecnológico y manejador canino) distribuidos por niveles como fundamentación, reentrenamiento, especialización y profundización en seguridad privada. En la resolución 4973 en el artículo 39 especifica "los cursos de fundamentación para cada ciclo con una intensidad mínima horario de cien (100) horas, excepto el curso de fundamentación de manejador canino que tendrá una intensidad mínima de doscientas (200) horas." (Superintendencia de Vigilancia y Seguridad Privada, 2001, p.2).

Es necesario reseñar, los criterios de aprobación que se encuentra en la Resolución 4973 en el artículo 45 para cada ciclo en especial de fundamentación por parte del estudiante, previo a la expedición de la certificación de aprobación del curso:

Tabla 1. Criterios de aprobación curso de fundamentación vigilante.

\begin{tabular}{|c|c|}
\hline Área & $\begin{array}{l}\text { Porcentaje de Mínimo } \\
\text { Aprobación }\end{array}$ \\
\hline $\begin{array}{l}\text { Procedimientos de Seguridad } \\
\text { Privada y Área técnica }\end{array}$ & 80 \\
\hline Armamento y Tiro & 70 \\
\hline $\begin{array}{l}\text { Socio-Humanística, Aspectos } \\
\text { Legales, Manejo de Emergencias y primeros auxilios, } \\
\text { Defensa Personal y acondicionamiento Físico }\end{array}$ & 60 \\
\hline Asistencia actividades académicas & 100 \\
\hline
\end{tabular}

Fuente: Síntesis elaborada por la autora con base Supervigilancia Resolución 4973 de 2011

Es importante señalar que los criterios de al $100 \%$ a las sesiones y la comprensión aprobación del Curso de Fundamentación para Vigilantes tienen el objetivo de garantizar la idoneidad del estudiante mediante la asistencia en la tabla 1. 
En relación al contenido curricular, la de Fundamentación del Ciclo de Vigilantes, Resolución 4973 en el Capítulo VII del artícu- que deben impartir de forma obligatoria las lo Tercero discrimina cada una de las áreas Escuelas de Capacitación que cuenta con el temáticas y el número de horas del Curso licenciamiento otorgado por la SVSP:

Tabla 2. Currículo de curso de fundamentación vigilantes Colombia.

\begin{tabular}{|c|c|c|}
\hline ÁREA & CURSO DE FUNDAMENTACIÓN CICLO VIGILANTES & HRS \\
\hline \multirow{6}{*}{ Socio-Humanística } & Inducción & 1 \\
\hline & Relaciones humanas e interpersonales & 4 \\
\hline & Ética y prevención de adicciones & 4 \\
\hline & Manejo de estrés & 3 \\
\hline & Calidad del servicio y atención al cliente & 6 \\
\hline & Subtotal de Horas & 18 \\
\hline \multirow{10}{*}{ Aspectos legales } & Derechos Humanos & 3 \\
\hline & $\begin{array}{l}\text { Normas Superintendencia y clases de Servicios de VSP, } \\
\text { modalidades y medios }\end{array}$ & 2 \\
\hline & Constitución Política & 2 \\
\hline & Nociones de derecho penal y laboral & 3 \\
\hline & $\begin{array}{l}\text { Decreto } 2535 \text { de } 1993 \text { ( normas sobre armas, municiones y } \\
\text { explosivos) }\end{array}$ & 2 \\
\hline & Código de Policía y código de convivencia ciudadana & 2 \\
\hline & Actuación en la escena del incidente ley 906 de 2004 & 2 \\
\hline & $\begin{array}{l}\text { Relación con las autoridades, grados y distintivos de la fuerza } \\
\text { publica }\end{array}$ & 2 \\
\hline & $\begin{array}{l}\text { Decreto } 3222 \text { de } 2002-\text { Redes de Apoyo y Solidaridad } \\
\text { Ciudadana }\end{array}$ & 3 \\
\hline & Subtotal de Horas & 21 \\
\hline \multirow{7}{*}{$\begin{array}{l}\text { Procedimientos } \\
\text { de Seguridad Privada }\end{array}$} & Factores de inseguridad, procedimientos de vigilancia & 8 \\
\hline & $\begin{array}{l}\text { Redacción, metodología para la recolección de información y } \\
\text { toma de decisiones }\end{array}$ & 4 \\
\hline & Modus operando delincuencial & 4 \\
\hline & Conocimiento del entorno & 2 \\
\hline & Control de acceso (sistemas electrónicos, garret) & 7 \\
\hline & Prevención de la delincuencia & 3 \\
\hline & Subtotal de Horas & 28 \\
\hline
\end{tabular}

continúa 


\begin{tabular}{|l|l|l|}
\hline \multirow{4}{*}{ Área técnica } & Características, identificación, y búsqueda de explosivos & 6 \\
\cline { 2 - 3 } & Conocimiento y empleo de equipos de comunicación & 6 \\
\cline { 2 - 3 } & Conocimiento y manejo de armas no letales & 4 \\
\cline { 2 - 3 } $\begin{array}{l}\text { Manejo de } \\
\text { Emergencias } \\
\text { y primeros auxilios }\end{array}$ & Subtotal de Horas & $\mathbf{1 6}$ \\
\hline \multirow{2}{*}{$\begin{array}{l}\text { Defensa Personal y } \\
\text { acondicionamiento }\end{array}$} & Control de emergencias y primeros auxilios & 5 \\
\cline { 2 - 3 } Físo & Suevención y manejo de equipos de control de incendios & 2 \\
\hline \multirow{2}{*}{$\begin{array}{l}\text { Armamento y } \\
\text { Tiro }\end{array}$} & Defensa personal & $\mathbf{7}$ \\
\cline { 2 - 3 } & Subtotal de Horas & 4 \\
\hline & Conocimiento de armas de fuego & $\mathbf{4}$ \\
\cline { 2 - 3 } & Ejercicio práctico de tiro & 4 \\
\cline { 2 - 3 } & Subtotal de Horas & 100 \\
\hline
\end{tabular}

Fuente: Supervigilancia Resolución 4973 de 2011, p.6

Ahora bien, plan curricular, formulado por parte de la SVSP se caracteriza por contar con un mínimo de 100 horas distribuido en siete módulos que cubre desde los aspectos humanísticos, legales, procedimiento de seguridad privada, área técnica, atención en primeros auxilios, defensa personal hasta el manejo de armas. Es necesario precisar, que el Curso de Fundamentación para Vigilantes es indispensable como requisito ejercer profesionalmente como guardia de seguridad, condición para la contratación por parte de las empresas y obligación para continuar los niveles de formación reentrenamiento (30 horas), especializaciones
(60) y profundización (30). Para respaldar esta afirmación, en la Resolución 4973 en el artículo 41 denominado desempeño de las funciones:

Para desempeñar las funciones de Vigilante, Escolta, Supervisor, Operador de Medios Tecnológicos y Manejador Canino en seguridad y vigilancia privada, es requisito fundamental, haber aprobado con anterioridad, en escuela o departamento de capacitación vigilancia y seguridad privada, debidamente autorizada por la superintendencia, el curso de fundamentación correspondiente a cada ciclo. (Superintendencia de Vigilancia y Seguridad Privada, 2011, p. 3). 
Lo anterior demuestra cómo el proceso educativo de los vigilantes deber ser riguroso y cumplir con unos requerimientos en cuanto a la culminación de ciclos que fundamentan diversos temas la seguridad.

\section{CURRÍCULO DEL CURSO DE FUNDAMENTACIÓN CICLO DE VIGILANTE EN BUENOS AIRES ARGENTINA}

Al revisar un referente internacional acerca de la formación en seguridad privada se expone el caso de Buenos Aires Argentina que guarda relación en materia normativa y los lineamientos curriculares. Se propone presentar brevemente, las principales normas que rigen el sector de vigilancia privada. En primer lugar, la ley 1913 de 2005 "regula la actividad de seguridad privada establece entre las funciones de la Dirección General de Seguridad Privada la de inscribir y llevar un registro de los institutos de formación para vigiladores". (Legislatura Ciudad Autónoma de Buenos Aires, 2011, p.1). Es ne- cesario aclarar, mediante esta ley se faculta a la Dirección General de Seguridad Privada para ejercer, control, inspección y vigilancia sobre los servicios que prestan las escuelas o institución de formación en seguridad privada (establecimiento públicos o privados aprobado por la ley) en la ciudad de Buenos Aires.

En el Decreto 446/06 en el Anexo II, contempla "desempeño de los Institutos de Formación como al contenido de la currícula de los cursos de capacitación para el personal que presta servicios de vigilador de seguridad privada en jurisdicción de esta Ciudad" (Legislatura Ciudad Autónoma de Buenos Aires, 2010, p.1). En el anexo II se define con exactitud los objetivos por modulo, el contenido curricular, el número de horas por modulo. Sin embargo, los criterios de aprobación del curso carecen de la especificidad como se describe en la normatividad colombiana (Ver Tabla 1Criterios de aprobación Curso de Fundamentación Vigilante). A continuación, se presenta las directrices en el contexto de la ley argentina:

Tabla 3. Criterios de aprobación curso de fundamentación vigilante Argentina

\begin{tabular}{|l|l|}
\hline \multicolumn{1}{|c|}{ Área } & \multicolumn{1}{|c|}{ Porcentaje de Mínimo Aprobación } \\
\hline Procedimientos de Seguridad Privada y Área técnica & No se define específicamente \\
\hline Armamento y Tiro & No se define específicamente \\
\hline $\begin{array}{l}\text { Socio-Humanística, Aspectos Legales, Manejo de } \\
\text { Emergencias y primeros auxilios, Defensa Personal y } \\
\text { acondicionamiento Físico }\end{array}$ & No se define específicamente \\
\hline Asistencia actividades académicas & $80 \%$ \\
\hline
\end{tabular}

Fuente: Síntesis elaborada por la autora con base Disposición No. 63 -DGSPR/10 
En relación a los lineamientos de aprobación del curso de Fundamentación para Vigilador en el caso de Argentina, es muy incipiente mientras que, la normatividad Colombia el vigilante debe aprobar estas áreas con una calificación mínima: Procedimientos de Seguridad Privada $80 \%$, Armamento y Tiro $70 \%$ y Socio-Humanística, Aspectos Legales, Manejo de Emergencias y primeros auxilios, Defensa Personal y acondicionamiento Físico con $60 \%$. Es indispensable, en adelante SVSP realice una restructuración normativa para aumentar en forma escalonada los porcentajes de aprobación del Curso de Fundamentación en Colombia.

Por otro lado, en Buenos Aires en la Disposición No. 63 -DGSPR/10 se evidencia la preocupación de la Dirección General de Seguridad Privada por mejorar el desempeño de los vigiladores mediante la reestructuración de los currículos, el número de horas del curso de fundamentación Ciclo Vigilantes:

Para poder alcanzar una formación integral de las personas involucradas en la provisión de servicios de seguridad privada, deviene necesario incrementar la carga horaria de 60 hs a
70 hs., a fin de lograr un mayor grado de responsabilidad y profesionalización;

Que, además, se propende a que posean un alto grado de eficiencia e idoneidad, formándose a través de un plan de carrera con diferentes niveles, dándole las herramientas necesarias para poder actuar correctamente en la toma de decisiones, en las diferentes situaciones que se le pueden presentar. (Legislatura Ciudad Autónoma de Buenos Aires, 2010, p.1).

Además, en la Disposición No. 63 -DGSPR/10 en el Título II del artículo once se detalla el contenido curricular del Curso de Fundamentación para vigilantes que se denomina Curso Básico de Capacitación inicial, que cuenta con diez módulos distribuidos en 70 horas, que tiene por objetivo "proveer al cursante de los alcances y limitaciones de la tarea a desarrollar, en el marco de un servicio eficiente que tiende a la prevención y a la disuasión como guía de su accionar" (Legislatura Ciudad Autónoma de Buenos Aires, 2010, p.4). En la Tabla 4 Currículo de Curso de Fundamentación se resume los contenidos de por cada uno de los módulos: 
Tabla. 4. Currículo de curso de fundamentación vigilantes Buenos Aires Argentina.

\begin{tabular}{|c|c|c|}
\hline ÁREA & Curso Básico de Capacitación Inicial en Vigilancia & HRS \\
\hline $\begin{array}{l}\text { Seguridad y } \\
\text { Vigilancia }\end{array}$ & $\begin{array}{l}\text { Objeto de Seguridad, Perfil Técnico, Medios de Protección, Principios de operativos } \\
\text { fundamentales, Concepto de Riesgo, Modus Operandi delictual, Modalidad operativa en } \\
\text { el objetivo, nociones sobre terrorismo }\end{array}$ & 18 \\
\hline $\begin{array}{l}\text { Derechos } \\
\text { Humanos }\end{array}$ & $\begin{array}{l}\text { Nociones generales y antecedentes, Conceptos Básicos Protección Derechos } \\
\text { Humanos, Derechos y Libertades en la Constitución, Los Derechos Humanos y la } \\
\text { Reforma Constitucional, Contravenciones y Resolución de Conflictos }\end{array}$ & 10 \\
\hline $\begin{array}{l}\text { Nociones } \\
\text { Legales }\end{array}$ & $\begin{array}{l}\text { Conocimientos básicos en Constitución Nacional y Constitución de la Ciudad de } \\
\text { Buenos Aires, Concepto de Seguridad, Nociones de Derecho Procesal, Laboral y } \\
\text { Penal, Conceptos Básicos de ley de Armas y Explosivos, Obligaciones del Personal de } \\
\text { Seguridad Privada, Ética profesional y Habeas Data }\end{array}$ & 7 \\
\hline $\begin{array}{l}\text { Primeros } \\
\text { Auxilios }\end{array}$ & $\begin{array}{l}\text { Principios Generales, Concepto de Emergencia, Introducción a Primeros Auxilios, } \\
\text { Nociones elementales de Anatomía, Intervención de emergencias, clasificación y } \\
\text { tipos de emergencia, tipo de lesiones, Técnica de RCP Básica, Botiquín y elementos de } \\
\text { Emergencia y alcance de y limitaciones de la asistencia primaria y marco legal. }\end{array}$ & 5 \\
\hline $\begin{array}{l}\text { Lucha contra el } \\
\text { fuego }\end{array}$ & $\begin{array}{l}\text { Concepto de Fuego, Clasificación de los Combustibles, Concepto de Riesgo, Normas } \\
\text { de precaución y prevención, actuaciones ante siniestros, Uso de equipos de protección, } \\
\text { Conceptos de Plan de Seguridad y Plan de Evacuación, Riesgos Edilicios y Señalización } \\
\text { de Emergencias }\end{array}$ & 5 \\
\hline $\begin{array}{l}\text { Armas: } \\
\text { conocimiento y } \\
\text { manipulación }\end{array}$ & $\begin{array}{l}\text { Concepto de Armas, Organismo Regulador de uso de Armas RENAR, Agresivos } \\
\text { Químicos y Armas Electrónicas }\end{array}$ & 5 \\
\hline $\begin{array}{l}\text { Reglas Generales } \\
\text { de Atención de } \\
\text { Publico }\end{array}$ & $\begin{array}{l}\text { Conceptos de identificación de personas, técnicas de observación, Reconocimiento } \\
\text { del lugar de Trabajo, Lenguaje corporal, Control de Acceso personas, vehículos y } \\
\text { electrónico, Identificación de elementos utilizados para agredir, patrullaje y guardia, } \\
\text { actuación ante situaciones de emergencia }\end{array}$ & 5 \\
\hline $\begin{array}{l}\text { Seguridad } \\
\text { Edilicia }\end{array}$ & $\begin{array}{l}\text { Riesgos y amenazas más comunes en edificios, Procedimientos específicos en cada } \\
\text { situación y puertas de salida. }\end{array}$ & 5 \\
\hline $\begin{array}{l}\text { Práctica en la } \\
\text { conducción y } \\
\text { cuidado del can } \\
\text { de seguridad }\end{array}$ & $\begin{array}{l}\text { Aspectos Generales, Anatomía y características morfológicas del can, topología racial, } \\
\text { agresividad, conceptos breves de herencia y genética, Concepto de adestramiento, } \\
\text { Guardia y Defensa, Carácter y temperamento de los canes, Capacidad de reacción y } \\
\text { agresión, Relación Agente vigilador y can, Ley de protección del animal y Marco Legal. }\end{array}$ & 5 \\
\hline Comunicaciones & $\begin{array}{l}\text { Inducción y aspectos generales, Concepto de seguridad de las comunicaciones, } \\
\text { conocimientos de red telefónica, Aspectos Normativos, Registro Telefónico-Valor } \\
\text { judicial, código Q, código internacional de emergencia, nociones elementales de } \\
\text { mantenimiento de mantenimiento de equipos, Conceptos de Radio Operador, Cámaras } \\
\text { de Seguridad y Manejo del Domo y Procedimiento y Protocolos. }\end{array}$ & 5 \\
\hline & Total de horas de Formación & 70 \\
\hline
\end{tabular}

Fuente: Síntesis elaborada por la autora con base norma Disposición No. 63 -DGSPR/10 pp. 4-8 
Así mismo, en el artículo doce de la misma disposición, introduce la obligatoriedad a los vigilantes para seguir con su proceso de formación continua, "el vigilador deberá realizar el primer curso de actualización y adiestramiento al año de haber aprobado el Curso de Capacitación Inicial" (Legislatura Ciudad Autónoma de Buenos Aires, 2010, p.16). Mientras tanto, en la revisión de la normatividad colombiana no existe este tipo de precedentes de obligatoriedad para la formación continua de los mismos, es necesario replantear y evaluar la necesidad de un curso anual de actualización de carácter obligatorio para mejorar el desempeño y actualización en materia de los procedimientos y normatividad del sector de seguridad privada con la finalidad de mejorar el desempeño laboral en pro del servicio que se ofrece a la comunidad. Al mismo tiempo, al indagar la información es evidente que la normatividad Colombia introducido algunas reformar sustanciales con respecto al número de horas de formación para el curso de fundamentación en el artículo 39 de la Resolución 2852 de 2006 afirma "la intensidad mínima de los cursos es de 50 horas académicas a excepción de los especiales que será de 100 horas" (Superintendencia de Vigilancia y Seguridad Privada, 2006, p. 8).

\section{EVOLUCIÓN DE LOS SERVICIOS DE CAPACITACIÓN Y ENTRENAMIENTO EN SEGURIDAD PRIVADA}

Los antecedentes históricos en el periodo comprendido a principios del siglo $\mathrm{XX}$, puede demostrar que los modelos de la Administración Científica y la Teoría de la Administración Operacional Moderna, entraron en decadencia en la década de los sesenta y setenta en gran medida por los nuevos paradigmas productivos que replantearon el rol del hombre en el ámbito laboral, las técnicas de aprendizaje aplicadas en el contexto empresarial. Los nuevos modelos de organización del trabajo, transformaron el panorama en empresarial donde el aprendizaje en especial la educación no formal asume un rol protagónico para atender las exigencias de las organizaciones mediante el rediseño, formación y evaluación de los currículos para formar en competencias a los trabajadores con los mayores estándares de calidad y alineados a los objetivos corporativos.

A partir de la década del noventa, la seguridad privada experimenta un crecimiento exponencial y una diversificación inédita. En primer lugar, se consolida un conjunto de empresas que ofrecen servicios de vigilancia, control de accesos, custodia de personas y mercancías, seguridad electrónica y transporte de valores. Estas empresas son hoy cerca de un millar, de las cuales aproximadamente cien son relativamen- 
te grandes, incluyendo a un puñado de firmas trasnacionales que se han instalado en el país durante la última década y a algunas decenas de empresas con una larga trayectoria en el sector. En conjunto, estas empresas emplean alrededor de 150.000 trabajadores, la mayoría de ellos encargados de tareas de vigilancia.

Por otra parte, en el contexto latinoamericano en países como Colombia, Chile y Argentina, no fue ajena a los cambios que comprendían la regulación normativa desde los productos, servicios hasta el ejercicio profesional de los guardias de seguridad que comprendía ciclos de capacitación (curso de fundamentación, reentrenamiento, especialización y profundización) los lineamientos curriculares, intensidad horaria, y criterios de aprobación. En la década de los 90 según Lorenc, Khalil, y Guevara (2012) "la seguridad privada experimenta un crecimiento exponencial y una diversificación inédita. En primer lugar, se consolida un conjunto de empresas que ofrecen servicios de vigilancia, control de accesos, custodia de personas y mercancías, seguridad electrónica y transporte de valores" (p.2). En el caso de caso de Colombia, la Ley 61 de 1993 da origen a la Superintendencia de Vigilancia y Seguridad Privada y mediante el Decreto 356 de 1994 se expide el estatuto del sector para regular aquellas personas naturales y jurídicas que mediante licenciamiento ofrecen una amplia gama de productos y servicios del sector de seguridad privada como se describió en el capítulo dos.

En el grafico 1. Evolución de las empresas de capacitación y entrenamiento se presenta la información de las organizaciones que se les otorgo el licenciamiento para prestar los servicios capacitación y entrenamiento en el periodo comprendido entre 1994 y 2007. De acuerdo a estos datos estadísticos, se aprecia el crecimiento vertiginoso en la década de los noventa desencadenado por la expedición de estatuto de seguridad privada que incentivo la creación empresas dedicadas a las actividades de formación en el sector:

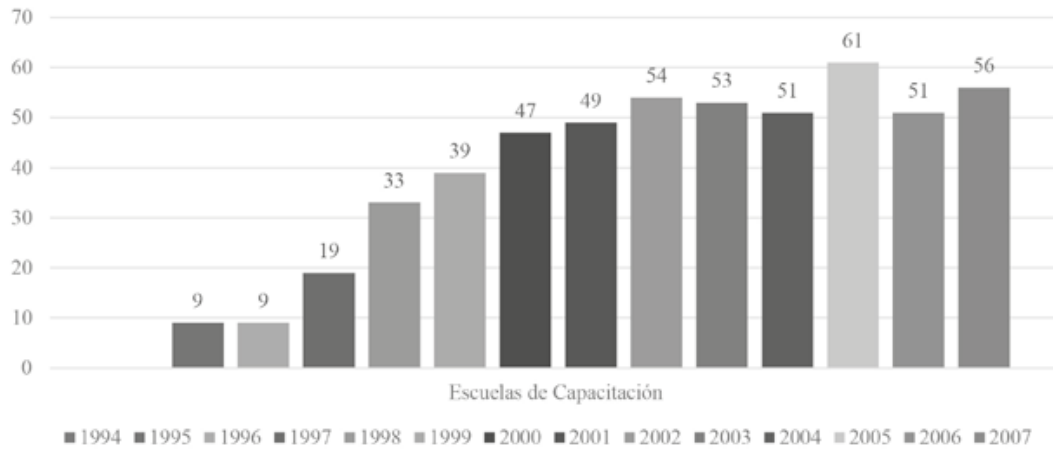

Grafico 1. Evolución de las empresas de capacitación y entrenamiento. Fuente: Adaptación de acuerdo a los datos de la autora Baracaldo (2014) 
La Cámara de Comercio de Bogotá en el año 2008 público la Caracterización de los servicios de vigilancia y seguridad privada en Bogotá, este estudio (exploratorio realizado a 822 vigilantes y 165 empresas del sector con un margen de confiabilidad $95 \%$ ) reúne una serie de datos relevante de la población que ejercer su oficio en el sector de seguridad privada en Colombia. Se observa, que la población que se desempeña como vigilantes supera la fuerza pública en un número significativo. Las empresas consultadas en manifiestan que cuentan con:

Aproximadamente 36.700 hombres disponibles para los diferentes servicios de vigilancia. El servicio que más personal concentra es la vigilancia con arma: 18.552 vigilantes. Ésta es una cifra importante si se considera que el pie de fuerza de la Policía Metropolitana de Bogotá es de aproximadamente 16.000 hombres. Cámara de Comercio de Bogotá, 2008, p.6).

De acuerdo a la investigación de la Cámara de Comercio en el 2007 , se estimaba que el $95 \%$ del vigilante son hombre y el $5 \%$ mujeres con un rango de edad de 28 a 44 años. Mientras tanto en Argentina, Lorenc, Khalil, y Guevara (2012) afirma "en el último trimestre de 2010, el 91\% de los vigiladores eran hombres y solamente $9 \%$ mujeres ubicándose en una categoría intermedia de individuos de 35 a 50 años de edad." (p.105). Al analizar las cifras, es evidente que predomina el ejercicio del oficio por parte de los hombres y la edad promedio en Colombia de 36 años y a su vez en Argentina de 42. Según Baracaldo (2014) presenta los datos suministrados por la Oficina Asesora de Planeación de la SVSP "en el 2013 el $89 \%$ son hombres y el $11 \%$ mujeres" (p.206). Es indudable, la participación activa en los últimos diez años por parte de las mujeres en Colombia va en aumento en el sector de seguridad privada.

En la Tabla No. 5 Distribución por sexo sector seguridad privada, las estadísticas son contundentes $86.16 \%$ de las mujeres ejercer el cargo de vigilantes, seguido $10.51 \%$ son operadoras de medio tecnológico: 
Tabla 5. Distribución por sexo sector seguridad privada 2014.

\begin{tabular}{|c|c|c|c|c|c|}
\hline \multirow[b]{2}{*}{ CARGO } & \multicolumn{2}{|c|}{ SEXO } & \multirow[b]{2}{*}{ TOTAL } & \multirow{2}{*}{$\begin{array}{c}\% \\
\text { Hombre }\end{array}$} & \multirow{2}{*}{$\begin{array}{c}\% \\
\text { Mujeres }\end{array}$} \\
\hline & HOMBRES & MUJERES & & & \\
\hline Vigilante & 172.194 & 21904 & 194.098 & 82,63 & 86,16 \\
\hline Escolta & 18.518 & 351 & 18.869 & 8,89 & 1,38 \\
\hline Supervisor & 10.666 & 400 & 11.066 & 5,12 & 1,57 \\
\hline Operador Medio tecnológico & 4.083 & 2.671 & 6.754 & 1,96 & 10,51 \\
\hline Manejador Canino & 2.724 & 90 & 2.814 & 1,31 & 0,35 \\
\hline Tripulante & 208 & 5 & 213 & 0,10 & 0,02 \\
\hline Total & 208.393 & 25.421 & 233.814 & & \\
\hline
\end{tabular}

Fuente: Adaptación de acuerdo a los datos de la autora Baracaldo (2014)

Por otro lado, la tendencia por cargo en el sexo masculino se refleja en el grafico 2, que permite una mayor comprensión de los datos estadísticos. Por ejemplo, los hombres se desempeñan como vigilante $82.63 \%$, escoltas $8.89 \%$, y supervisores $5.12 \%$. De acuerdo a la información estadística, resalta la tendencia en aumento de las personas que laboran en sector de seguridad privada por ende es necesario rediseñar el currículo del Curso de Fundamentación Vigilante para garantizar el mejor desempeño laboral que impacte positivamente en el cumplimiento de los objetivos de la organización y la seguridad ciudadana en el territorio nacional.

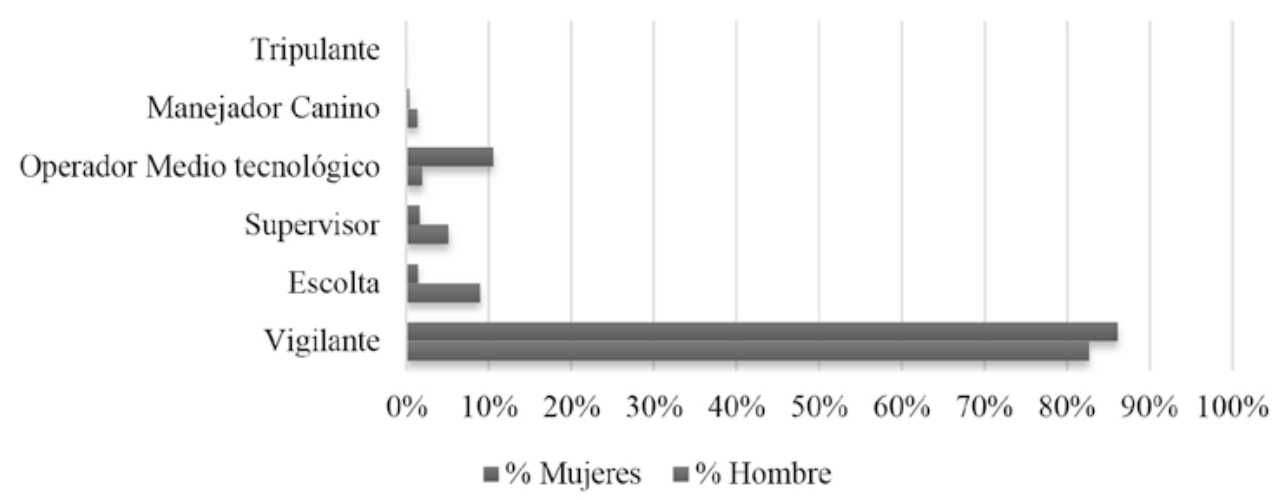

Grafica 2. Tendencia por cargo y sexo sector de seguridad privada Colombia 2014 Fuente: Adaptación de acuerdo a los datos de la autora Baracaldo (2014) 
Es preocupante al analizar los currículos del curso de Curso de Fundamentación de Vigilante en Colombia y Argentina, en el sentido de la corta dedicación al número de horas para el Módulo de Socio- Humanísticas que cuenta con 18 horas en el caso de Colombia, se carece de los contenidos curriculares detallados para aportar efectivamente a la formación integral de los guardias de seguridad. Al mismo tiempo, en Argentina los módulos Derechos Humanos y Reglas Generales de Atención Publico se estima un tiempo de 15 horas, equivalentes al componente humanísticos colombiano, con la gran diferencia demarcada en la Disposición N. 63 -DGSPR/10 que especifica al detalle los contenidos curriculares del módulo o área de formación que las escuelas de capacitación y entrenamiento ofrecen a sus alumnos. Además, al realizar la validación de los referentes normativos concernientes al sector de vigilancia y seguridad Privada en Argentina se evidencia, la Resolución Conjunta N. ${ }^{\circ} 1 / M J Y S G C / 13$ en la cual se menciona necesidad de:

Diseñar estrategias y políticas metropolitanas concernientes a un Sistema Integral de Seguridad de acuerdo a la Constitución y las Leyes de la Ciudad Autónoma de Buenos Aires, en coordinación con el Ministerio de Gobierno y Diseñar, promover, implementar y evaluar las políticas y programas educativos que conformen un sistema educativo único e integrado a fin de contribuir al desarrollo individual y social. (Ministerio de Justicia y Seguridad y Ministerio de Educación, 2013 p. 1).

En el contexto colombiano no se encontró este tipo de disposiciones que tienen la intencionalidad de mejorar el desempeño laboral de los guardias de seguridad, mediante una formación integral en gran medida por su interacción con la comunidad y los clientes con el fin de mitigar los riesgos (incendios, delincuencia común, primeros auxilios) que afecten la integridad de las personas e instalaciones que custodian.

\section{DISCUSIÓN}

Los resultados permitieron reflexionar que el sector de seguridad privada en Colombia, carece de estudios y que permitan determinar el impacto del currículo en el desempeño laboral de los vigilantes. Sin embargo, la tendencia del crecimiento del número del personal vinculado asciende a 233.814 al 2014 (ver Tabla 5. Distribución por sexo sector seguridad privada) reflejan la necesidad de fortalecer los procesos de formación y entrenamiento del personal que se desempeña en el sector pero en especial los guardias de seguridad que son 194.098 personas quienes deben cursar y aprobar el Curso de Fundamentación Vigilante, por el impacto que tienen su actividades en la organización y la comunidad en general. En Colombia en 2013, 
las empresas dedicadas a prestar los servicios Supervigilancia se visualizan en la siguiente formación según datos suministrados por la ilustración:

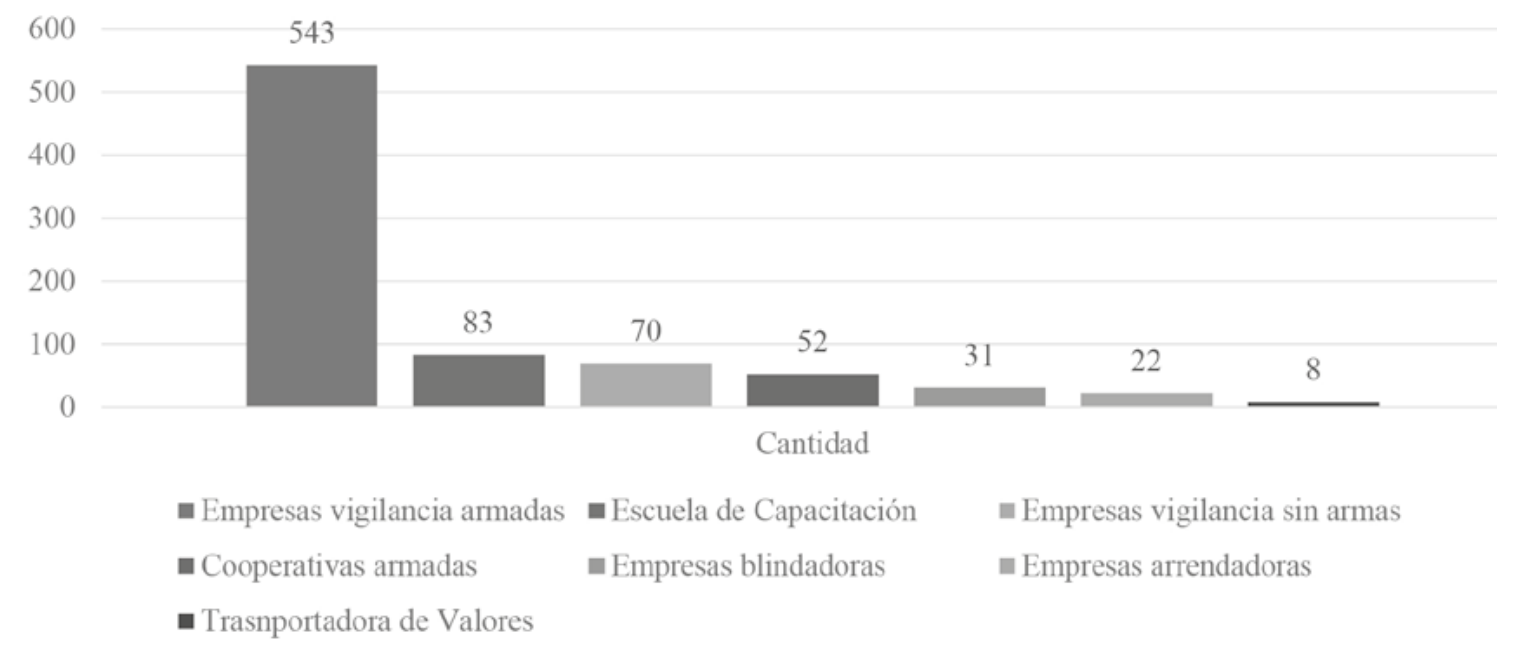

Grafico 3. Distribución empresas servicios seguridad privada en Colombia 2013.

Fuente: Adaptación de acuerdo a los datos de la autora Baracaldo (2014)

De los resultados presentados en los Gráficos N. 1 y 3 , se evidencia el incremento de las empresas dedicadas a prestar los servicios de formación, para el año 1995 (Grafico 1) se formalizaron 9 empresas y al 2013 en las bases de datos de la Supervigilancia registra $83 \mathrm{com}$ pañías debidamente acreditadas para ofertar el portafolio de servicios en Capacitación y Entrenamiento en contenidos curriculares del sector de seguridad privada en Colombia.

En relación del nivel de formación académica de los vigilantes o vigiladores la situación es crítica en Argentina como afirma Lorenc, Khalil, y Guevara (2012):
En lo que respecta al nivel educativo, quienes trabajan como vigiladores se distribuyen en dos grandes categorías que cuentan con un número similar de casos. Por un lado, $48 \%$ de los vigiladores tienen estudios primarios completos o secundarios incompletos: se trata, pues, de una mano de obra con un grado relativamente bajo de escolarización. Por el otro lado, $47 \%$ de los vigiladores han recibido una educación secundaria y superior: $33 \%$ terminó la escuela secundaria, $9 \%$ inició estudios universitarios sin concluirlos y $5 \%$ tiene estudios universitarios completos (p.106). 
En el caso de Colombia, los datos estadísticos presentan un horizonte sombrío con respecto al nivel educativo del personal que labora en el sector. Según la Cámara de Comercio en el estudio de 2008 al consultar a los 822 vigilantes acerca del grado de escolaridad se indicó que solo el " $4 \%$ primaria incompleta, el $14 \%$ cuentan con primaria completa, 25\% Educación Secundaria Incompleta, bachilleres $51 \%$ y solo el $5 \%$ tienen formación Técnico Universitario" (Cámara de Comercio de Bogotá, 2008, p.7). En relación al nivel educativo de los guardias de seguridad en Argentina y particular Colombia, el bajo nivel en educación primaria y secundaria se considera una preocupación por la responsabilidad y la imagen institucional que proyectan a la comunidad. Al mismo tiempo, los procesos capacitación y entrenamiento en el contexto laboral han estado de la mano al desarrollo de las compañías por la necesidad de dotar a los individuos de las competencias específicas (propias para ejecutar una profesión o oficio) para ejercer su labor y cumplir con los requerimientos de calidad de desempeño y el logro de los objetivos de la organización, como respuesta a esta situación las nuevas tendencias en el ámbito organizacional se habla de la formación por competencias para contribuir en el éxito del individuo y la organización.

La caracterización de la población que ejerce como guardia de seguridad tiene la intensión de describir el contexto laboral de las actividades específicas dentro de la organización y su rol en la sociedad como agente mitigador del riesgo asociado a las instalaciones y las personas que habitan en ellas. Los autores Lorenc, Khalil, y Guevara (2012) manifiesta:

Llama la atención que personas tan escolarizadas desarrollen una tarea que requiere, en apariencia, tan poca calificación. Sin embargo, el análisis de las prácticas laborales y la demanda de los empleados permite anticipar que algunas de las características que hoy resultan apreciables en un vigilador suelen ir asociadas a mayores niveles de estudio: trato cordial, comunicación, "buena presencia", capacidad de escritura y registro de datos, uso de ordenador (p.106).

Es claro al contrastar, los datos estadísticos de Colombia y Argentina referente al bajo nivel de formación de los guardias de seguridad es evidente que no cuentan competencias específicas (físicas, intelectuales, éticas y emocionales) para cumplir con las exigencias en el entorno laboral en el sector de seguridad privada.

Según, Bernal en el texto Introducción a la administración de las organizaciones menciona la importancia del: 
Proceso de formación tiene como propósito fundamental mejorar el rendimiento actual y futuro de los colaboradores de una organización mediante el perfeccionamiento de sus competencias técnicas y profesionales, y el enriquecimiento de sus conocimientos específicos, sus habilidades, sus destrezas y sus actitudes. Incluye los siguientes sus procesos: análisis de las necesidades, los objetivos, el plan y la evaluación de la formación. (Bernal, 2014, p. 239).

De acuerdo a la afirmación de Bernal y la coyuntura que atraviesan las empresas en un mundo más dinámico y globalizado, las organizaciones como las Supervigilancia y las Escuelas de Capacitación y Entrenamiento deben explorar los nuevos paradigmas como la Formación por Competencias, que está orientada a la formación integral para lograr la autorrealización personal de los individuos que a su vez impactan en los objetivos de las empresas. Vela (2004) realiza una aproximación interesante del concepto de competencia como "conjunto de conocimientos (saber), habilidades (saber hacer) y actitudes (saber estar y querer hacer) que, aplicados en el desempeño de una determinada responsabilidad o aportación profesional, aseguran su buen logro"(p.86).

Sin embargo, Tobón, Pimienta y García J (2010) definen el concepto de competencias desde un enfoque socioformativo "las competencias son actuaciones integrales ante actividades y problemas del contexto, con idoneidad y compromiso ético, integrando el saber ser, el saber hacer y el saber conocer en una perspectiva de mejora continua" (p.13). Es decir, las Escuelas de Capacitación y Entrenamiento en seguridad privada deben formar a los estudiantes con los conocimientos teóricos y a la vez deben enseñar a aplicarlos en problemáticas y actividades diarias integrando la dimensión ética con valores y actitudes proactivas para potencializar el desarrollo integral de los guardias de seguridad; esto implica que es fundamental el rediseño curricular del Curso de Fundamentación para vigilantes en cada uno de las áreas (ver Tabla 2) con el objetivo que los estudiantes aprendan a actuar desde la primera sesión de clase con base "en el saber hacer, el saber conocer y el saber ser (que integra el saber convivir), con el fin de alcanzar determinados propósitos pertinentes en el contexto" (Tobón, Pimienta, y García J, 2010,p.13).

De acuerdo, Tobón, Pimienta, y García J, (2010) afirman "El Instituto CIFE (Centro de Investigación en Formación y Evaluación) ha identificado cuatro grandes enfoques de las competencias a nivel mundial: funcionalista, conductual, constructivista y socioformativo o enfoque complejo". En el contexto colombiano y en particular en las escuelas capacitación y 
entrenamiento en seguridad privada requieren formar seres integrales que estén en capacidad de actuar profesionalmente frente a los retos de las organizaciones y clientes. Por ende, el enfoque socioformativo se amolda a las necesidades de las empresas en la medida gestiona los recursos y espacios para formación integral de los guardias de seguridad, para que estén en la capacidad de solucionar los problemas actuales y futuros en los diferentes contextos (laboral, sociedad, familiar).

En el libro Formación Integral y Competencias del Dr. Tobon (2010), describe la diferencia del enfoque socioformativo respecto a otros:

Este enfoque es similar a otros enfoques de las competencias en aspectos tales como: (1) tiene en cuenta el estudio del contexto, (2) busca diseños curriculares más integrativos que con respecto al currículum tradicional; (3) se basa en estrategias didácticas que tienen en cuenta los diferentes saberes de las competencias, y (4) la valoración se basa en criterios y evidencias". Este enfoque socioformativo le da mucha importancia al compromiso ético y coloca este aspecto como eje transversal en la formación de las competencias. (Tobón, 2010, p.36).
El análisis de los diferentes enfoques funcionalista, conductual, constructivista y socioformativo o enfoque complejo, de este último, resalta por la simplicidad de metodología (se aplicado en países como Colombia, México, Bolivia, Venezuela, Chile) y se centra en la formación integral del individuo mediante la formación por competencias y como eje transversal los valores aplicados al contexto para movilizar la gestión educativa; mediante la mediación intencional de los docentes por esto el enfoque complejo es más factible por ejecutar y evaluar para lograr el mejoramiento continuo del proceso educativo.

Por otra parte, los autores Tobón, Pimienta, y García J, (2010) mencionan que el enfoque socioformativo tiene tres componentes fundamentales: formulación de la competencia a partir del análisis de problemas; construcción de criterios y planeación de evidencias. Además, las secuencias didácticas son, sencillamente, conjuntos articulados de actividades de aprendizaje y evaluación que, con la mediación de un docente, buscan el logro de determinadas metas educativas, considerando una serie de recursos (Tobón, Pimienta, y García J, 2010, p.21).

Para ilustrar esta metodología de la formación por competencias en el enfoque socio formativo: 


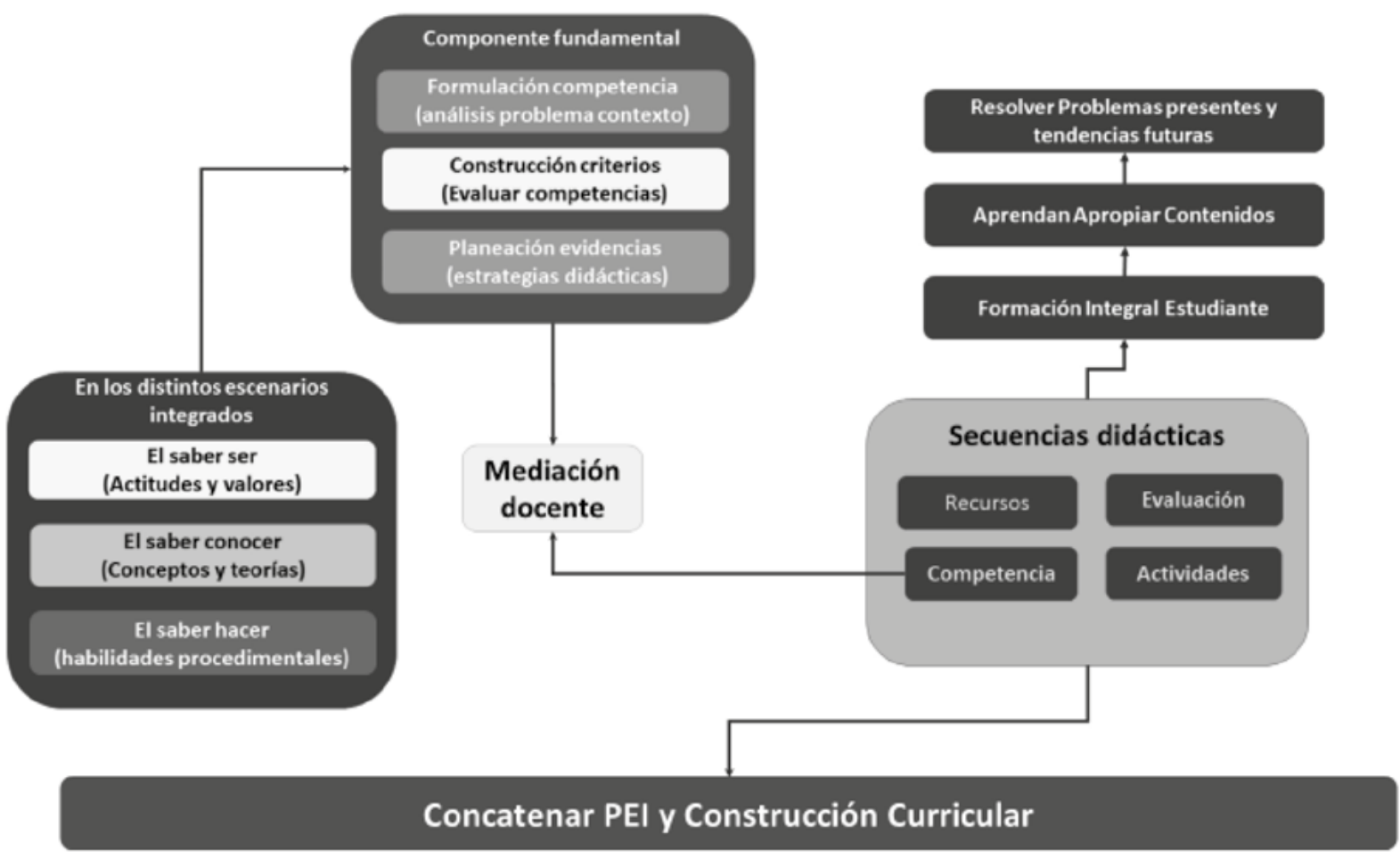

Grafica 4. Enfoque socio formativo

Fuente: Adaptación de acuerdo a los datos del Dr. Tobón (2010)

Como se puede notar las competencias en el enfoque socio formativo están compuestas por competencias a fortaleces los conocimientos en el saber conocer, saber ser y saber hacer, para que el sujeto de esa forma aprenda afrontar los diferentes retos que le presentan en el desarrollo profesional, además de apropiar los contenidos de una manera significativa logrando que estos se mantengan a través del tiempo y no se olviden fácilmente y por otra parte se fortalecen las habilidades necesarias para que los sujetos pueden crear alternativas de solución para las diferentes problemáticas sociales que existen en el medio aportando así a la transformación de la sociedad, propiamente a través del desarrollo de su profesión.

\section{CONCLUSIONES}

Lo anterior permitió reconocer que es indispensable que la Superintendencia de vigilancia y seguridad privada por competencia dentro de su normatividad realice una actualización 
periódica de los contenidos curriculares y defina claramente cada uno de los objetivos de formación de los módulos y a su vez en los cursos de fundamentación, reentrenamiento, especializaciones y la profundización que deben guardar coherencia con el PEI de las escuelas de capacitación y entrenamiento, en materia de calidad y evaluación de los mismos con la finalidad de mejorar la formación integral de guardias de seguridad.

Al igual se identificó que la Supervigilancia debe trabajar conjuntamente con el Sena para sensibilizar a las ochenta y tres Escuelas de Capacitación y Entrenamiento, en la adopción de la metodología de formación por competencias que gira en torno de una situación problema en el contexto laboral, actividades entrelazadas con la adopción de recursos pedagógicos y la evaluación de la formación para mejorar el desempeño integral de los guardias de seguridad.

No obstante, es importante que el rediseño curricular del Curso de Fundamentación para vigilantes se deber hacer con la participación de diferentes actores mediante articulación y trabajo en equipo de la Mesa Sectorial del Servicio Nacional de Aprendizaje SENA (participación voluntaria de los actores gobierno, sector productivo y la academia) con el objetivo de evaluar el contenido curricular que debe estar reestructurado con los PEIS, para guardar coherencia y la inclusión de la nueva normatividad como el Código de Policía, Código de la Infancia y Adolescencia y Protocolo de operación para el servicio de vigilancia y seguridad privada en el sector educativo (este lineamiento indica que vigilantes debe aprobar como mínimo el grado undécimo).

También se pudo observar que la norma colombiana, el artículo 42 de la Resolución 4973 de 2011 se menciona los requisitos mínimos que debe validar las Escuela de Capacitación y Entrenamiento para las personas interesadas es aprobar el Curso de Fundamentación Ciclo Vigilantes, es cuestionable para los guardias de seguridad solo se le exija la aprobación de quinto de primaria. Se propone un plan escalonado a corto plazo para incentivar la aprobación de educación básica media y bachillerato para mejorar el desempeño integral medio puesto que, ellos desempeñan un rol activo en el sector de seguridad privada y al mismo tiempo, modificar este artículo en el ítem d) tener aprobado como mínimo al grado un décimo para los vigilantes.

Para finalizar, en el estudio realizado por Cámara de Comercio en el año 2008, al indagar a los guardias de seguridad sobre la calidad los módulos expresaron que solo el $87 \%$ han realizado el Curso de Fundamentación. Así mismo, el $46 \%$ de los individuos expresan que 
al cursar los niveles de reentramiento, actualización y especialidades son monótonos y de calidad baja. Al aplicar la metodología de Formación por Competencias propuesta por los autores Tobón, Pimienta, y García se puede tener un impacto positivo en la medida que se dinamiza el proceso de formación, mediante la formulación de las competencias específicas, las actividades y evidencias se aplican al contexto del sector de seguridad privada para generar en el individuo la capacidad de aportar a la solución problemas actuales y futuros, interactuar con la comunidad mediante la comunicación oral y escrita, el manejo de equipos de trabajo tales como alarmas, equipos de comunicación, sistemas de información en pro de mitigar las acciones que afecten las personas y las edificaciones que tienen bajo su custodia.

\section{REFERENCIAS}

Baracaldo, M.(2014). Colombia Vigilancia, seguridad privada y manejo de armas 1994-2013: Policía y seguridad pública. Recuperado de: https:// dialnet-unirioja-es.ezproxy.umng.edu.co:2518/ servlet/articulo?codigo $=4899428$

Bernal, C. (2014). Introducción a la administración de las organizaciones: Enfoque global e integral. Recuperado de: http://www.ebooks7-24. com/?il=3406
CámaradeComerciodeBogotá,(2008).Caracterización de los servicios de vigilancia y seguridad privada en Bogotá. Recuperado de: https://www.google. com.co/url?sa=t\&rct=j\&q=\&esrc=s\&source= web\&cd $=1 \&$ cad $=$ rja\&uact $=8 \&$ ved $=0$ ahUKEwinOZ R4evWAhUKjZAKHVagCqkQFggkMAA\&url= http\%3A\%2F\%2Fwww.supervigilancia.gov.co\%2F\%3Fidcategoria\%3D3938\%26download\%3DY\&usg=AOvVaw2GEWRjOtWK6TVpZcR1sIPs

Casarini, M, (2005). Teoría y Diseño Curricular. México: Editorial Trillas.

Catalano, A., Avolio, S, y Sladogna M. (2004). Competencia Laboral: Diseño curricular basado en normas de competencia laboral. Buenos Aires, Argentina: Banco Interamericano de Desarrollo. Recuperadode:https://www.google. com/url?q=http://www.oei.es/historico/etp/ diseno_curricular_basado_normas_competencia_laboral.pdf\&sa=U\&ved=0ahUKEwittdHjnr TWAhUEIsAKHW2VBc0QFggEMAA\&client=inte rnal-uds-cse\&usg=AFQjCNEGIRXLWW7xujiAbgGoLh2rYPGsKw

Kemmis, S. (1986). El curriculum: más allá de la teoría de la reproducción. España: Ediciones Morata. 
Koontz,H., Weihich. H., y Cannice. M. (2012). Administración una perspectiva global y empresarial. México: McGraw-Hill Interamericana. Recuperado de: http://www.ebooks7-24. com/?il=640

Legislatura Ciudad Autónoma de Buenos Aires. (2006). Decreto 446/06 de Reglamentación Ley 1913. Recuperado de: http://www.buenosaires. gob.ar/sites/gcaba/files/decreto446_0_0.pdf

Legislatura Ciudad Autónoma de Buenos Aires. (2010). Disposición No. 63- DGSPR/10. Recuperado de: http://www.buenosaires.gob. ar/sites/gcaba/files/17_0_0.pdf

Legislatura Ciudad Autónoma de Buenos Aires. (2011). Disposición 372 DGSPR /11. Recuperado de: http://www.buenosaires.gob.ar/sites/gcaba/files/11_0_0.pdf

Lorenc, F., Khalil, E., Guevara, T. (2012). El nuevo proletariado de la vigilancia: los agentes de seguridad privada en Argentina. Trabajo y sociedad, 19. Recuperado de: http://www. scielo.org.ar/scielo.php?script=sci_arttext\&pi$d=S 1514-68712012000200006 \&$ lng $=e s \&$ tIn $g=e s$.

Ministerio de Justicia y Seguridad y del Ministerio de Educación de Argentina. (2013). Resolución Conjunta 1/MJYSGC/13. Recuperado de: http:// cdn2.buenosaires.gob.ar/dgspr/resolucion_ conjunta_2.pdf

Pereira, F. y Sousa, J. (1990). El origen de las Escuelas de Artes y Oficios en Galicia, el caso compostelano. España: Historia de la Educación, 9 Recuperado de: http://hdl.handle. net/10366/79514

Purpura, P. (2006). Manual de capacitación para personal de seguridad. México: Editorial Limusa \& Grupo Noriega Editores.

Ramírez, C. (2010). Fundamentos de administración. (3a. ed.) Ecoe Ediciones. Recuperado de http://www.ebooks7-24.com/?il=93

Superintendencia de Vigilancia y Seguridad Privada de Colombia. (1994). Decreto 356 del 11 de febrero de 1994. Recuperado de: http://www. supervigilancia.gov.co/?idcategoria $=1045$

Superintendencia de Vigilancia y Seguridad Privada de Colombia. (2001). Decreto 2187 del 12 de octubre de 2001. Recuperado de: http://www. supervigilancia.gov.co/?idcategoria $=1045$

Superintendencia de Vigilancia y Seguridad Privada de Colombia.(2006). Decreto 2355 del 17 de julio de 2006. Recuperado de: http://www.supervigilancia.gov.co/?idcategoria $=1045$ 
Superintendencia de Vigilancia y Seguridad Privada de Colombia. (2008). Resolución 5679 de 29 de diciembre de 2008. Recuperado de: http://www. supervigilancia.gov.co/?idcategoria $=6467$

Superintendencia de Vigilancia y Seguridad Privada de Colombia. (2011). Resolución 4973 de 27 de julio de 2011. Recuperado de: http://www.supervigilancia.gov.co/?idcategoria $=57155$

Tobón, S. (2010). Formación integral y competencias: pensamiento complejo, currículo, didáctica y evaluación. Bogotá Colombia: ECOE Ediciones.
Tobón, S., Pimienta J., y García J. (2010). Secuencias didácticas: aprendizaje y evaluación de competencias. Recuperado de: https://www. researchgate.net/profile/Sergio_Tobon4/publication/287206904_Secuencias_didacticas_ aprendizaje_y_evaluacion_de_competencias/ links/567387b708ae04d9b099dbb1.pdf

Vela, L. (2004). Gestión por Competencias, el reto compartido del crecimiento personal y de la organización. Madrid-España: Esic Editorial. 